Sociohistórica, nº 39, e025, 1er. Semestre de 2017. ISSN 1852-1606

Universidad Nacional de La Plata.

Facultad de Humanidades y Ciencias de la Educación.

Centro de Investigaciones Socio Históricas

\title{
Las intervenciones electorales del Partido Socialista en la ciudad de Buenos Aires antes de la Ley Sáenz Peña (1896-1910)
}

\author{
Electoral interventions of the Socialist Party in the city of Buenos \\ Aires, before the Saenz Peña Laws (1896-1910)
}

\section{Lucas Poy*}

* Consejo Nacional de Investigaciones Científicas y Técnicas (CONICET). Instituto de Historia Argentina y Americana "Dr. Emilio Ravignani" - Universidad de Buenos Aires, Argentina | lucaspoy@gmail.com

\section{PALABRAS CLAVE}

Partido Socialista

Argentina

Elecciones

Campañas electorales

\section{KEYWORDS}

Socialist Party

Argentina

Elections

Electoral campaigns

\section{RESUMEN}

El objetivo de este artículo es examinar la participación del Partido Socialista argentino en las elecciones de la ciudad de Buenos Aires en el período anterior a la reforma impulsada por el presidente Roque Sáenz Peña a comienzos de la década de 1910. El análisis se basa en un relevamiento de fuentes partidarias y de la prensa comercial de la época: si bien se ubica en el campo de la historia de los trabajadores y las izquierdas, desarrolla un diálogo con la bibliografía que ha examinado las características del régimen político y las distintas coyunturas de la política facciosa porteña. Los resultados de la pesquisa sugieren la necesidad de ir más allá de la constatación de la importancia dada por el partido a la táctica electoral, para adentrarse en un examen concreto de sus prácticas. Sus conclusiones apuntan a la capacidad que demostró el PS para mejorar su desempeño en las elecciones porteñas en la segunda mitad de la década de 1900.
The goal of this article is to examine the Argentine Socialist Party's electoral interventions in the city of Buenos Aires, in the period before the electoral reform promoted by President Roque Sáenz Peña in the early 1910s. It draws upon a study of the party's journal and the commercial press. Even though it is rooted in the field of labor history, the article also discusses the bibliography that examined the main characteristics of the political regime and the political struggles in Buenos Aires during the period. The results of this research suggest that it is important to go beyond the statement of the prominent place that the Socialist Party gave to electoral participation, in order to address the specific ways in which this participation was put forward. The conclusions of the paper indicate the capacity showed by the Socialist Party to improve its performance in the elections in the second half of the decade.

Cita sugerida: Poy, L. (2017). Las intervenciones electorales del Partido Socialista en la ciudad de Buenos Aires antes de la Ley Sáenz Peña (1896-1910). Sociohistorica, 39, e025. https://doi.org/10.24215/18521606e025 


\section{Introducción}

En el último tercio del siglo XIX, la sociedad argentina experimentó un acelerado proceso de transformación: bajo el impulso de una fuerte llegada de capitales extranjeros, se consolidó una estructura capitalista integrada en forma dependiente en el mercado mundial. Este proceso implicó un rápido crecimiento demográfico, consecuencia en gran medida de la llegada de inmigrantes europeos, y dio lugar a la aparición de un moderno y combativo movimiento obrero, que ya en la última década del siglo se había convertido en un destacado actor político. En este marco, se consolidaron también de manera temprana las primeras organizaciones y corrientes políticas de esa naciente clase obrera. En disputa con la corriente anarquista, que tendría en Argentina uno de sus más importantes centros a nivel mundial, surgió y se estructuró una importante corriente socialista, vinculada a la Segunda Internacional.

El socialismo argentino, cuyos primeros pasos habían tenido como protagonistas a communards franceses, en la década de 1870, y a exiliados socialdemócratas alemanes, en la de 1880, conoció un proceso de desarrollo y unificación en la última década del siglo, que dio lugar a la constitución formal del Partido Socialista en el congreso constituyente de 1896.En consonancia con los planteos de la socialdemocracia internacional de la época, para el PS la “acción política” constituía uno de los pilares fundamentales de su actividad, en tanto lo distinguía de sus adversarios anarquistas. Para los socialistas, las huelgas y otros episodios de la llamada "lucha económica" representaban una forma importante pero limitada de lucha de la clase trabajadora. La tarea principal era la lucha en el terreno político, y en este sentido desde sus más tempranos orígenes se plantearon la necesidad de organizarse para la intervención en las elecciones. ${ }^{1}$

Los socialistas se daban a esta tarea en un país cuyo régimen político garantizaba el sufragio a todos los varones argentinos adultos: en no pocas ocasiones la prensa partidaria haría referencia al contraste con otros países donde la lucha por obtener el sufragio universal constituía una tarea central para los socialdemócratas. Este amplio derecho al voto y la realización de elecciones en forma periódica y sin interrupciones, de todos modos, estaban atravesados por un complejo sistema de prácticas distintas de las que conocemos para períodos posteriores a la sanción del conjunto de leyes que establecieron una profunda reforma del sistema electoral, por iniciativa del presidente Roque Sáenz Peña, a comienzos de la década de 1910. Los episodios electorales estaban dominados por una lucha entre distintas maquinarias políticas estrechamente vinculadas a la clase dominante y se caracterizaban por la efectiva participación de un reducido número de electores, la mayor parte de los cuales pertenecía, sin embargo, a la naciente clase trabajadora. Dado que esta clase obrera estaba constituida en una proporción muy importante por inmigrantes extranjeros, para el PS la agitación en pro de la participación política de los trabajadores iba de la mano de una campaña por la naturalización de los mismos. $\underline{2}$

En este marco, este artículo examina la efectiva participación en las elecciones por parte de la militancia del Partido Socialista en la ciudad de Buenos Aires, en el período anterior a la ley Sáenz Peña. Se trata de un aspecto que ha sido escasamente estudiado en la literatura que abordó la historia del partido. Por lo general, las investigaciones se han limitado a señalar que el PS asignaba una importancia destacada a la participación electoral—algo sin duda correcto, aunque a veces se 
pierde de vista que dicho rasgo era compartido por el conjunto de la socialdemocracia de la época, y de ningún modo una excepcionalidad argentina-y en todo caso a hacer referencia a la elección de 1904, en la cual el PS logró la elección de Alfredo Palacios como diputado nacional. $\underline{3}$

En general, de hecho, los análisis sobre la performance electoral del PS tuvieron como punto de partida el período posterior a la ley Sáenz Peña, una etapa en la que efectivamente se combinaron una serie de muy buenos resultados electorales, con el ingreso de numerosos dirigentes socialistas al Parlamento, y al mismo tiempo una importante transformación interna en el partido, tanto en el plano organizativo como fundamentalmente en el político. Carecemos, sin embargo, de una más precisa comprensión sobre la participación del PS en las elecciones en la etapa anterior, y ello en dos aspectos que se complementan. Por una parte, porque persiste un cierto sentido común que se limita a caracterizar que en los años anteriores a 1912 la performance electoral del PS fue muy pobre: un análisis en torno al cual se desarrollaron distintas interpretaciones acerca de la incapacidad de la propuesta política del partido de interpelar efectivamente a la clase obrera en el contexto de los mecanismos electorales fraudulentos (Falcón, 1987; Torre, 2012). Por otra parte, porque no sabemos prácticamente nada sobre la dinámica concreta que tomó la militancia del partido en torno a las campañas electorales y el modo en que ello da cuenta del desenvolvimiento y la organización del mismo como fuerza política.

Nuestro objetivo es avanzar en una comprensión más detallada del modo concreto en que el partido llevaba adelante su intervención en las elecciones. Para ello, el artículo examina las presentaciones electorales del PS en la ciudad de Buenos Aires, desde 1896-la primera ocasión en que se presentó una lista socialista—hasta 1910, la última vez que se votó con las reglamentaciones anteriores a la Ley Sáenz Peña. El recorte geográfico se debe a que, durante gran parte del período, la ciudad de Buenos Aires fue el único distrito en el cual el PS presentó candidatos: a lo largo de la década de 1900, y con dificultad, el partido comenzó a presentar candidaturas en otras localidades del país, sobre todo de la provincia de Buenos Aires y de Santa Fe. Se trata de más de una decena de elecciones para diputados nacionales por la capital federal-incluimos los casos de elecciones complementarias realizadas debido a la renuncia o muerte de algunos parlamentarios-, en tanto durante este período el PS rechazaba presentar candidatos a senadores y a la presidencia de la nación. Dividimos este conjunto en dos subperíodos. El primero, entre 1896 y 1902, está caracterizado por resultados marginales y por una evidente dificultad del PS para competir con las fuerzas de los partidos del régimen. En la segunda etapa, que extendemos desde 1904 hasta 1910 un contexto marcado por tensiones internas entre los grupos facciosos y una "persistente fragmentación de la clase dominante" (Castro, 2007)— el socialismo local fue capaz de desenvolver, en una serie de distritos del sur de la ciudad, una efectiva intervención en las jornadas electorales, que redundó en una sensible mejoría de los resultados obtenidos.

\section{Las presentaciones electorales entre 1896 y 1904}

Debido a su carácter fundacional y a su habitual inclusión en las obras elaboradas por el propio partido, es relativamente conocida la primera presentación electoral del socialismo local, en marzo 
de 1896. Además de los extremadamente exiguos resultados electorales reconocidos por las autoridades — en torno a un centenar — también son conocidas y han sido analizadas las tensiones que surgieron en el período previo a la propia presentación electoral, como resultado de la decisión de la dirección del partido de solo permitir la participación en la asamblea que elegiría a los candidatos a aquellos militantes que contaban con la ciudadanía argentina (Falcón, 2011; Poy, 2014). En cualquier caso, lo sucedido en esos primeros meses de 1896 no fue un episodio excepcional sino el punto de partida de una serie de prácticas que el naciente partido repetiría en los años sucesivos.

Para el PS, la participación en las elecciones constituía una de las más importantes-en muchos casos, la principal - tareas políticas para sus dirigentes y militantes: en este sentido, toda la organización se ponía en movimiento para participar en la campaña, y ella se desenvolvía en una serie de instancias. La primera era la convocatoria de una "asamblea local” que tenía la tarea de designar a los candidatos a diputados. Por lo general se realizaba un par de semanas antes de la elección: en algunos casos, como en 1900, se hizo apenas siete días antes del comicio, aunque luego de 1904 comenzó a hacerse con mucha más antelación. En un segundo momento, la asamblea daba paso a la campaña electoral propiamente dicha: desde entonces, la lista de candidatos era publicada en la portada del periódico y se publicitaban las diferentes actividades de difusión y agitación de las propuestas del partido. También era habitual la inclusión de extractos de la reglamentación vigente, con el objetivo de instruir a los militantes y simpatizantes socialistas sobre los procedimientos electorales. La campaña se desenvolvía, incluso desde este período temprano, a través de actividades y asambleas públicas. Era común que estas actividades se realizaran por las noches y sobre todo los domingos, el momento en que una mayor cantidad de trabajadores podía participar de ellas. En 1902 se anunciaba que las agrupaciones y centros podían pasar a retirar "carteles y manifiestos” ya impresos para la difusión y agitación electoral. Se imprimían, asimismo, miles de boletas con los nombres de los candidatos y el periódico difundía los horarios de funcionamiento de los locales en los cuales los votantes podían concurrir a solicitar boletas, además de los datos de los responsables de la fiscalización.

Para entender la dinámica del proceso de “producción” de resultados en este período es fundamental tener presente cuatro rasgos clave del proceso electoral, precisamente los que se modificarían luego de 1912. En primer término que el derecho a voto (masculino) era "universal”- es decir que podían votar todos los ciudadanos mayores de edad, sin ninguna distinción según ingresos o extracción social, aunque con la exclusión de mujeres y extranjeros - pero no obligatorio. En segundo lugar, que no existía un padrón general en el que estuvieran incluidos todos los ciudadanos con derecho a voto, sino que para cada elección éstos debían inscribirse en un registro cívico. En tercer lugar, que el voto no era secreto, sino que se emitía públicamente sea en forma oral o por escrito al llegar el votante al sitio de votación. En cuarto y último lugar, que no existía representación proporcional ni un criterio para la inclusión de las minorías, sino que se votaba por "lista completa": es decir, si había siete cargos en disputa, el votante debía votar por siete candidatos, y los siete más votados resultaban electos. Si bien en términos formales estos podían no ser todos de la misma lista, lo habitual es que así ocurriera: por lo tanto, aquella lista que obtenía una mayoría simple de votos se 
quedaba con todos los cargos en disputa. Como veremos, esta legislación fue parcialmente modificada en 1902, cuando se introdujo el sistema de voto uninominal: el mismo se utilizó, sin embargo, solamente en la elección de 1904 y en dos votaciones complementarias, para luego volverse al sistema anterior.

La “producción” de los resultados electorales, en este marco, comenzaba con el proceso mismo de inscripción a los registros, e incluso antes, con el desarrollo de prácticas clientelares en torno a la tramitación de la naturalización. Pero la instancia decisiva era la propia jornada de la elección, donde la clave era el control físico del espacio de votación y la movilización de grupos de votantes afines a uno u otro sector. Conscientes del problema, desde sus primeras presentaciones electorales los socialistas advertían a sus militantes sobre la necesidad de prepararse para esta disputa. En la elección de abril de 1898 se publicaron una serie de instrucciones a los fiscales, que en primer lugar recomendaba a los militantes que "se presenten en los atrios a primera hora para poder inmediatamente formar los grupos”. Los fiscales socialistas debían pasar por la sede del comité electoral en las noches del viernes y sábado previo a la votación. No solo debían controlar la elección sino que también tenían la tarea de "designar uno o dos compañeros de la parroquia encargados de repartir boletas a proximidad del comicio”, y al término de la elección solicitar los certificados con los resultados (LV, 9/4/1898).

Las crónicas de lo ocurrido en estas primeras presentaciones electorales dan cuenta de una debilidad de las fuerzas del joven socialismo local, cuyos militantes y fiscales eran en muchos casos directamente impedidos de ingresar a los lugares de votación. La Vanguardia denunciaba que los votantes y grupos socialistas eran “dispersados” y sus boletas destruidas. El periódico socialista, por otra parte, reproducía extensamente las denuncias de medios de prensa comerciales porteños, que hablaban de "simulacro electoral” y se extendían en consideraciones sobre las prácticas irregulares en aquellas elecciones en las que, debido a las vicisitudes de la política facciosa de la época, no estaban alineados con el oficialismo (LV, 14/3/1896, 16/4/1898 y 17/3/1900).

La actividad política de los socialistas en torno a las elecciones tenía un último y destacado episodio con las denuncias contra el fraude. Esto implicaba, ya desde la primera presentación electoral en 1896, la publicación en el órgano partidario de duros ataques contra la “política criolla”, pero poco después se sumó a ello la organización de actividades y meetings callejeros de protesta. La denuncia se convertía en una nueva oportunidad para convocar a los trabajadores a una actividad de denuncia de las prácticas políticas de la oligarquía.

El más importante de estos meetings fue el realizado en 1898. El 16 de abril, poco después de la elección, La Vanguardia era encabezada por un llamado a movilizarse "contra el fraude, la corrupción y la farsa política”, contra el "atentado a los derechos del ciudadano, el secuestro, las prisiones y la ostentación ridícula de fuerza”. El PS reclamaba la anulación de la elección, del padrón vigente y la reforma de la ley electoral (LV, 16/4/1898). El acto se realizó el domingo 17 de abril, por la tarde, y según La Vanguardia contó con la participación de dos mil personas, que partieron de Plaza Lorea y se dirigieron a la Plaza San Martín. En su discurso, Justo buscó diferenciarse de los partidos que habitualmente denunciaban el fraude, pero eran partícipes del mismo régimen. En realidad, destacó, el PS no luchaba en abstracto por la pureza del sufragio, 
como reivindicaban algunos opositores, sino que lo reclamaba para obtener reivindicaciones concretas: "el pueblo consciente”, señaló, "sufre demasiado de las cargas que pesan sobre él para tener ningún tipo de platonismo, ni siquiera el platonismo del voto; si quiere el sufragio libre y auténtico es para servirse de él en la defensa de sus mermados intereses, en apoyo de sus ideas de política práctica” (LV, 23/4/1898).

En el período 1896-1902, en suma, se configuraron una serie de rasgos fundamentales de la dinámica de intervención socialista en las campañas electorales de la ciudad de Buenos Aires. Esto implicó, en primer lugar, la consolidación de una línea que atribuía un lugar destacado a la "acción política” y a la participación electoral como una parte fundamental de ella, en consonancia con la orientación general de la socialdemocracia de la época. El Partido Socialista concurría a las elecciones para convocar a los trabajadores a elegir “entre los que no representan más que el fraude, la mentira y los bajos intereses de una clase rica pero ignorante, y los que representan los verdaderos intereses del pueblo" (Oddone, 1983: 203).La participación en las elecciones era vista, en este marco, como un episodio en la disputa por la conciencia de los trabajadores: el objetivo era que éstos demostraran su conciencia de clase y, al mismo tiempo, su condición de ciudadanos honestos, en tanto el PS emergía como representante de la transparencia y la honestidad frente a la descomposición moral de la "política criolla".

Pero la concurrencia a las elecciones también implicó otros aspectos menos estudiados, que hacían a la práctica concreta de intervención de los socialistas en los comicios: el desenvolvimiento de una campaña por la naturalización de los extranjeros y su inscripción en los registros cívicos, la puesta en marcha de una organización interna que promovía instituciones partidarias específicas para la lucha electoral, la planificación de actividades proselitistas y, por último pero no menos importante, la preparación de la militancia para las tareas de fiscalización, así como la organización de actividades posteriores para denunciar las irregularidades.

Si estos rasgos marcarían fuertemente las particularidades de la intervención electoral socialista por un período prolongado, advertimos también que, en esta primera etapa, el PS encontró muy serias dificultades para poder obtener algún éxito en las propias jornadas electorales. En efecto, el cuadro general era el de una "producción de resultados" completamente dominada por las maquinarias políticas de los partidos y facciones del régimen, en la cual los socialistas eran incapaces de intervenir en forma satisfactoria. A esto se sumaba el cierre parcial de la crisis política que tuvo lugar con la llegada de Roca a la presidencia por segunda vez, en 1898. En las elecciones de 1900, por caso, la “asamblea local” se convocó recién para el 3 de marzo, una semana antes de las elecciones del día 11: en contraste con la elección de 1898, ahora el clima era de bajísimas expectativas, luego del gran fraude de la elección anterior y en el marco de la consolidación del roquismo. Tal como señala Martín Castro, las elecciones legislativas de marzo de 1900 fueron “paradigmáticas por la carencia de competencia electoral real, por la omnipresencia del PAN en la política provincial y por la escasa movilización de los votantes y de acción proselitista de parte de las distintas facciones políticas” (2012: 81).

En este marco, no solo la denuncia posterior a las elecciones ocupó menos espacio e importancia que dos años antes, sino que surgieron incluso discusiones internas acerca de la utilidad de 
presentarse a los comicios. En el informe del comité ejecutivo al tercer congreso del partido, en junio de ese mismo año, se caracterizaba en efecto que era "indiscutible que centenares de ciudadanos no adheridos al partido y algunos miembros de él, se abstuvieron de inscribirse, convencidos de que las elecciones resultarían una farsa infame, y llegadas las elecciones el número de abstencionistas aumentó debido a una discusión iniciada en La Vanguardia respecto a si el partido debería o no concurrir a los atrios” (LV, 2/6/1900).

Sin embargo, las cosas cambiarían poco después. Las elecciones de 1902 mostraron, en la ciudad de Buenos Aires, una competencia entre la máquina política del roquismo y una lista "antiacuerdista” representada por figuras como Sáenz Peña y Cantón, lo cual era en buena medida un producto de las movilizaciones de un sector de la “opinión” porteña que habían tenido lugar en el invierno del año anterior (Castro, 2012: 86; Rojkind 2006). En cualquier caso, y a pesar de que otra vez los resultados electorales habían sido muy magros, La Vanguardia publicó luego de esos comicios una crónica de Adrián Patroni, en la que relataba la actividad desenvuelta tanto el día de la elección como en las jornadas previas y llegaba a conclusiones mucho más optimistas que dos años antes. “Abandonamos las mesas”, decía, “con el espíritu más retemplado, convencido de que la mayor parte de los ciudadanos que se abstienen de cumplir sus deberes cívicos pretextando que es imposible luchar contra el fraude, parten de un principio falso: pues si todos se inscribieran, se interesaran por depurar los padrones, evitando más tarde que en la inmaculación de conjueces no intervengan los caudillos y empresarios electorales, y luego los escrutadores exigieran a cada votante la comprobación de su personalidad, es seguro que el triunfo sería de los ciudadanos honestos”. Y concluía: “los miembros del Partido Socialista debemos convencernos de que están en nuestra propaganda, actividad y ejemplo los medios de purificar las prácticas electorales y abatir a la política criolla” (LV, 15/3/1902).

Las conclusiones de Patroni, en efecto, no eran patrimonio exclusivo de su habitual optimismo y tenacidad militante, sino que expresaban también las de un PS que dejaba en claro su decisión de insistir en la intervención electoral, aun a pesar de los muy bajos resultados obtenidos. Como veremos en la segunda parte de este artículo, en la etapa que se inicia con la elección de 1904 esta insistencia comenzaría a dar algunos frutos.

\section{Los socialistas y su desafío a la “política criolla” entre 1904 y 1910}

Las elecciones de 1904 se realizaron con una nueva legislación, la ley 4.161 aprobada en el verano del año anterior, poco después de la huelga general de noviembre de 1902, y en el marco de una fuerte represión sobre el movimiento obrero. La reforma era consecuencia de un debate político al interior de la clase dominante en torno a lo que se advertía como un problema serio de legitimidad del régimen político. Según Martín Castro, la reforma reveló “las intenciones de Roca por buscar una salida a la crisis política abierta con la fractura del Partido Nacional y por limitar las opciones políticas de la oposición” (2012: 92). El proyecto presentado por el Poder Ejecutivo establecía “un sistema de escrutinio por circunscripción uninominal para la elección de diputados, para lo cual proponía dividir la Argentina electoral en 120 circunscripciones” (de Privitellio, 2006). Se 
modificaba también el sistema de inscripción en los padrones, en tanto quitaba la tarea a los municipios para "dejarla en manos de comisiones ad hoc compuestas por tres ciudadanos sorteados entre los veinte máximos contribuyentes de la circunscripción” (ídem). El proyecto original contemplaba también la implantación del voto secreto, algo que fue finalmente rechazado en el Senado

Si bien La Vanguardia no realizó ninguna valoración de los debates legislativos sobre la reforma electoral ni lanzó una intervención al respecto-durante esas semanas el periódico partidario realizaba una edición de emergencia, debido al estado de sitio-lo cierto es que desde la segunda mitad de 1903 el PS se preparó de manera mucho más rigurosa que antes para participar en los comicios de 1904.Una de las novedades más significativas fue la creación y actividad sistemática de una “comisión electoral” en el seno del Concejo Nacional, la máxima autoridad partidaria en ese momento. La comisión comenzó a funcionar en agosto de 1903, es decir, a más de seis meses del comicio, se reunía semanalmente y tenía en sus manos centralizar todas las actividades vinculadas a las elecciones. En su primera reunión, resolvió "publicar un folleto de propaganda electoral exponiendo el programa mínimo”. Debido a que la reforma electoral establecía el sistema de representación uninominal para cada sección, el partido decidió asimismo que cada agrupación local—cuyos límites tendían a adaptarse a los de las secciones electorales, algo que quedaría poco tiempo más tarde establecido de manera formal y estatutaria-elegiría a su candidato a diputado. Con la presencia de miembros de la comisión, los distintos centros fueron haciéndolo en agosto y septiembre de 1903.

La comisión también se ocupaba de organizar la recolección de fondos para la campaña y de citar a sus reuniones a militantes de los diferentes centros. Al mismo tiempo centralizaba la tarea de hacer presentaciones y quejas por ciudadanos que no hubieran sido empadronados correctamente. También se recomendaba a todos los empadronados que concurrieran a las dependencias respectivas para retirar sus libretas, debido a que un modo habitual de encarar el fraude era quedarse con aquellas que no hubieran sido retiradas. En octubre se resolvió enviar una circular a todos los militantes que no aparecían en el padrón "para que manifiesten las causas de ello” (LV, 10/10/1903). Gracias a este temprano impulso, la campaña política de los socialistas se fortaleció. La sección de La Vanguardia dedicada a las actividades de los centros traía información sobre diversas actividades político-electorales en los barrios y en los locales: bailes, rifas y otras actividades financieras, reuniones de propaganda, agitaciones en las plazas.

La elección de diputados se realizó el domingo 13 de marzo de 1904 y la fecha iba a quedar en la historia de las izquierdas en nuestro país e incluso más allá de él, en tanto consagró al joven abogado Alfredo Palacios como el "primer diputado socialista de América”. Palacios se convirtió así en uno de los nueve diputados electos ese día — se votó en la mitad de las circunscripciones en que había sido dividida la capital—, accediendo al congreso gracias a menos de un millar de votos en la sección $4^{\circ}$, del barrio de la Boca, en un clima político porteño caracterizado por una agudización de la competencia y la lucha facciosa que enfrentaba al oficialista Partido Nacional, al mitrista Partido Republicano y al pellegrinista Partido Autonomista. Tal como han señalado varios autores, la consagración del diputado socialista fue posible no solo por el nuevo sistema de 
representación uninominal sino sobre todo por las divisiones y luchas facciosas entre estos distintos sectores de la "política criolla”, lo cual contribuyó a sumar votos para la candidatura socialista, en particular gracias al apoyo del Partido Republicano en ese distrito (Torre, 2012, Castro, 2012: 132). $\frac{4}{}$ Ello no aparecía, sin embargo, en el balance del PS, que celebró ampliamente la victoria obtenida en La Boca y la caracterizó como una indiscutible reivindicación de la corrección de la orientación política asumida. ${ }^{5} \mathrm{El}$ contraste con el balance fuertemente negativo de la práctica de la huelga general, y en particular de la táctica seguida por los anarquistas y la Federación Obrera en el conflicto de noviembre de 1902, no podía ser más evidente. Para el PS, la constancia y la tenacidad de una línea favorable a la acción política comenzaba a mostrar sus frutos: en uno de los distritos obreros por excelencia, la elección de un diputado socialista demostraba que una vez que los trabajadores se convertían en "electores conscientes”, capaces de distinguir entre sus adversarios de clase y aquellos que realmente defendían sus intereses, el camino podía quedar allanado para un crecimiento de las fuerzas socialistas.

La legislación que establecía un régimen de votación uninominal fue anulada poco después de las elecciones de 1904: una nueva reforma, aprobada durante la gestión de Manuel Quintana, resolvió retornar al régimen de lista completa y nuevamente la propuesta de implementar el voto secreto fue bloqueada y rechazada en el trámite de debate parlamentario. El diputado Palacios se manifestó en contra de la nueva reforma, y el PS volvió a defender su posición favorable a un sistema de representación para las minorías: lo cierto, en cualquier caso, es que la nueva legislación volvía a dificultar al extremo las posibilidades del PS de repetir el éxito de 1904, en tanto la lista triunfante en toda la capital era la que consagraba todos los diputados. La reforma de 1905, no obstante, no impidió que los socialistas reforzaran su orientación y desenvolvieran en la segunda mitad de la década de 1900 una fuerte intervención en las campañas electorales. A pesar de que no logró obtener una nueva banca parlamentaria, en esos años el PS obtuvo un significativo crecimiento electoral en la ciudad de Buenos Aires, que marcan una diferencia clara con el período previo.

En esta etapa, los socialistas mantuvieron y profundizaron el tipo de actividades proselitistas que se había configurado en los primeros años. La conformación de un “comité electoral central” ponía de manifiesto la importancia dada por la organización a la cuestión y contribuyó a centralizar las actividades vinculadas a los comicios. Además de la habitual difusión de materiales propagandísticos y colocación de afiches, era común la organización de actos y manifestaciones callejeras. El comité electoral, asimismo, promovía y llevaba adelante presentaciones ante los poderes públicos respecto a irregularidades en el padrón, en la etapa previa a la elección, así como denuncias por el fraude, en las semanas posteriores.

En las elecciones de 1906, 1908 y 1910, por otra parte, las mismas jornadas de votación fueron un escenario de lucha política mucho más explícita que antes entre los socialistas y los aparatos políticos de los partidos tradicionales. Es evidente un cambio respecto a lo ocurrido en el período anterior a 1904, cuando el PS era más bien un convidado de piedra en una jornada completamente dominada por las máquinas políticas. Es cierto que, a mediados de la década, era el conjunto de la dinámica electoral porteña la que estaba atravesando un período de cambios y mostraba un 
escenario más competitivo: en buena medida desde que un sector de las facciones políticasagrupadas en 1906 en la llamada Coalición Popular—salió al cruce de los caudillos afines al Partido Nacional, apelando a una mayor movilización de lo que llamaban la “opinión pública”, la organización de comités parroquiales, y por supuesto la compra de votos (Castro, 2012: 178-179 y 192-193). $\underline{6}$ Es importante no perder de vista, de todas formas, que más allá de estas modificaciones es posible observar un ostensible desarrollo y consolidación de la acción socialista, que lograba en ocasiones terciar en estas competencias electorales con un planteo que se oponía frontalmente al voto venal y disputaba incluso el espacio callejero en las fechas de elección a las distintas listas que dominaban la elección.

En efecto, si bien en las secciones más alejadas del centro, donde casi no existían locales socialistas y la fiscalización era escasa, particularmente en el oeste y norte de la ciudad, la situación seguía siendo muy dificultosa, $\underline{\underline{Z}}$ en una serie de distritos del centro y el sur los socialistas eran ahora activos protagonistas de la competencia electoral, disputando y en ocasiones triunfando ante las fuerzas oficialistas. Los distritos más fuertes de los socialistas eran por supuesto La Boca $\left(4^{\circ}\right.$ sección, San Juan Evangelista), pero también Barracas ( $3^{\circ}$, Santa Lucía), San Cristóbal Norte ( $8^{\circ}$ ) y San Telmo (12 , Concepción). En consecuencia, también eran mucho más detalladas las crónicas publicadas en La Vanguardia en los días posteriores a los comicios. En ellas se relataban los hechos ocurridos en la jornada electoral, pero no solo encontramos las habituales denuncias de corrupción y fraude sino también crónicas de la intervención y actividad de los socialistas.

Es posible advertir una correlación directa entre los resultados electorales y el peso político, organizativo y militante que los socialistas podían desplegar en el distrito, particularmente en los días de la elección. En La Boca, "la cuarta de fierro", era donde los socialistas obtenían triunfos y donde su militancia se podía advertir en todo el barrio. Ya en la elección que consagró a Palacios, en 1904, y más allá de los votos que llegaron de parte de otros sectores políticos, se había puesto de manifiesto el peso de los socialistas en el distrito. Según Oddone,

...nunca se había visto un entusiasmo igual en el barrio. Carros, carruajes, lanchas, repletos de hombres, mujeres, niños, llevando banderas rojas, inscripciones, alegorías, recorrieron durante todo el día la sección haciendo propaganda y sembrando entusiasmo y alegría frente a los comités de la "política criolla”, que no conocían más medio de “convencer” al electorado que el dinero y la promesa personal (1983: 224).

En la misma línea, una crónica publicada en La Vanguardia en ocasión de las elecciones realizadas en noviembre de 1906 permite apreciar el contraste con las lacónicas y sufridas notas de años previos:

El local del centro, ubicado en la calle Almirante Brown, desde el sábado último estuvo repleto de concurrencia. En las calles, durante las horas de elección faltaron los automóviles y los coches, característica de los días electorales; solo circularon carritos y chatas desde los que los compañeros llevaban a todas partes su palabra de aliento. En pos de cada vehículo con votantes, los muchachos, ciudadanos del mañana, corrían vivando al Partido Socialista y cantando los himnos populares, mientras desde los 
balcones y ventanas grupos de señoritas saludaban y aplaudían (LV, 27/11/1906).

Los candidatos socialistas, junto a decenas de militantes, solían recorrer las diferentes mesas en distintas circunscripciones, a menudo en automóvil. También se intentaba tener coches a disposición para transportar votantes a las respectivas mesas. Según una crónica de 1908, en la Boca, "gruesos grupos de ciudadanos recorrían las calles vivando al Partido y haciendo una intensa propaganda en pro de las candidaturas socialistas. Coches y carros cruzábanse, trasladando a los electores de un punto a otro, y dejando caer a su camino manifiestos y listas”. Dos años más tarde se describía a "una gran chata, engalanada con banderitas rojas y manifiestos de todas clases y llevando más de 80 ciudadanos, paseaba por delante de los comicios y del comité nacional, repartiendo boletas e invitando a los ciudadanos a votar por el partido socialista” (LV, 15/3/1910).

En una etapa donde el voto era un derecho exclusivo de los varones, es interesante destacar el rol que jugaban las mujeres en la campaña de los socialistas, un aspecto que era especialmente resaltado incluso por medios de prensa ajenos al movimiento obrero. ${ }^{8}$ En 1906 , una crónica de $L a$ Nación destacaba que en la Boca "el elemento femenino ha tomado parte activa ayer bajo la bandera socialista, realizando trabajos de propaganda en favor de su causa”. En Barracas, según el mismo matutino, los socialistas habían introducido "una forma yanqui de conseguir adeptos: por medio de lindas muchachas obreras que, vestidas de rojo, ocupaban carros que recorrían los puntos más frecuentados, bregando por el triunfo de sus candidaturas” (LN, 12/3/1906).

Una crónica de La Vanguardia de 1904 reivindicaba a "unas valerosas obreras socialistas demostrando todo el entusiasmo que tienen por la causa, distribuyeron boletines a los electores en la décima circunscripción (...) Llevaban como distintivo rojo clave prendido a la bata. Indiferentes, enemigos, todos las miraban con simpatía, pensando quizás que solo el socialismo es capaz de producir, en la Argentina, donde reinan tantos prejuicios, una demostración de fe tan sencilla y sincera” (LV, 26/3/1904). Según La Prensa: “en automóviles y carruajes recorrían los comicios varias señoritas, enarbolando pequeñas banderas rojas, y ellas exhortaban a los ciudadanos a cumplir con el deber de sufragar, a la vez que distribuían hojas volantes en las que se leían inscripciones como estas: No vendáis vuestro voto” (LP, 14/3/1910).

En el día de la elección, la disputa era no solo política sino también física. Haciendo un balance posterior a las elecciones de 1910, y en un poco habitual reconocimiento de la utilización de prácticas que llegaban a la violencia, La Vanguardia argumentaba que en los comicios se había demostrado "el propósito de defender el derecho político con toda energía, empleando, si es necesario, para arrollar la farsa y la ignominia del oficialismo que se instala cínicamente en la calle, los procedimientos de fuerza” (LV, 15/3/1910). En efecto, las crónicas dan cuenta de cómo los socialistas enfrentaban abiertamente a sus adversarios. En la elección de 1906, según La Vanguardia, un grupo de personas se había quedado hasta media tarde en el local de la Coalición en el barrio de La Boca, "sin decidirse a llegar hasta las mesas, esperando siempre que el precio de los votos aumentara”. A esa hora, sin embargo, “el diputado Palacios, teniendo conocimiento de que el club de referencia estaba convertido en un garito, se dirigió allí. Su llegada ocasionó el desbande de esos electores” (LV, 27/11/1906). 
En 1908, La Prensa informaba que en La Boca se había producido “un pequeño incidente” porque "el comité socialista había comprobado que se compraban libretas cívicas en el club autonomista del distrito, y esto determinó al doctor Palacios a concurrir a dicho club, donde increpó por tal conducta a los ciudadanos y a la policía que toleraba la violación de la ley electoral” (LP, 19/10/1908).También ocurría en otros barrios del centro y sur de la ciudad: en marzo de 1910, $L a$ Prensase refería a un “desorden” en un comité autonomista en Balvanera, cuando

...un grupo de socialistas, dirigidos por el doctor Alfredo L. Palacios detuvieron el automóvil cerca del comité y comenzaron a hacer propaganda en contra y repartir manifiestos socialistas. En ese momento se produjo el desorden, y después de silbidos y palabras hostiles que se dirigieron ambos grupos, el socialista fue atacado por otro que salió del comité; uno de estos últimos personalizó el ataque contra el doctor Palacios y se asegura que se tomaron a golpes de puño (LP, 14/3/1910).

El mismo día había ocurrido algo similar en Barracas: “un grupo de socialistas se estacionó, como a las diez de la mañana, frente al comité de la Unión Nacional de la sección $3^{\circ}$, situado en la calle Aristóbulo del Valle, y protestó contra la compra y venta del voto. Esta actitud dio margen a un incidente que pudo tener consecuencias graves, si no hubiera intervenido oportunamente la policía seccional” (LP, 14/3/1910).El mismo episodio era relatado por La Vanguardia:

...los compañeros indignados ante la impudicia de los agentes de Balestra, que remataban libretas a 3 y 5 pesos, hicieron propaganda moralizadora. Notado esto por los instrumentos de Balestra se originó un serio altercado. El Mosquito, tipo ruin al servicio del vividor liberal, insultó a nuestros compañeros; y otros elementos de este individuo sacaron a relucir sus revólvers, originándose un tumulto que no tuvo mayores consecuencias (LV, 15/3/1910).

En la misma elección, también en Barracas, “un grupo de compañeros socialistas jugó una mala pasada a un caudillo de Balestra. Invitados por éste a vender el voto, se fingieron venales y acompañados por él, fueron en coche, en dirección al comicio. Pero en el camino lo acariciaron tiernamente con los puños”. En la Boca, mientras tanto, “un club de la Unión Nacional había establecido subasta en la vereda. Nuestros compañeros se dirigieron al grupo e increparon a los venales, repartiéndoles boletas. Se produjo un incidente entre el doctor Palacios y Lavarello, quien inmediatamente telegrafió al director Balestra que los socialistas de la $4^{\text {a }}$ estaban bravos” (LV, $15 / 3 / 1910) \cdot \underline{9}$

\section{Los resultados electorales}

Entre 1896 y 1902 es prácticamente imposible obtener alguna precisión sobre la magnitud de las votaciones socialistas. Así lo advertían los propios socialistas en la época. En efecto, en este primer período, el PS despreciaba por completo los números de votos informados por las autoridades, por considerarlos carentes de todo valor. El 13 de marzo de 1906 se decía que "nuestro partido, en las elecciones de 1896 (...) obtuvo 100 votos. De las elecciones subsiguientes [1898, 1900 y 1902] no 
se tienen datos precisos ni aproximados. El voto socialista debió permanecer estacionario” (LV, $13 / 3 / 1906) . \underline{10}$

Es que, como apuntamos anteriormente, las elecciones de 1904 abrieron una nueva etapa. Esto se debió no solo a la mayor extensión y preparación realizada para la campaña y por supuesto a la consagración de Palacios, sino también en términos cuantitativos. La mayor capacidad política y organizativa para intervenir en los comicios, analizada en la sección anterior, le permitió al PS obtener un crecimiento en las elecciones del resto de la década.

Figura 1. Votos obtenidos por el Partido Socialista en la ciudad de Buenos Aires

\begin{tabular}{|c|c|c|c|c|c|c|c|c|}
\hline Circunscripción & $\begin{array}{c}13 \\
\text { Mar } \\
1904\end{array}$ & \begin{tabular}{|c|}
24 \\
Jul \\
1904 \\
\end{tabular} & \begin{tabular}{|c|}
16 \\
Jul \\
1905 \\
\end{tabular} & $\begin{array}{c}11 \\
\text { Mar } \\
1906\end{array}$ & $\begin{array}{c}25 \\
\text { Nov } \\
1906\end{array}$ & $\begin{array}{c}8 \\
\text { Mar } \\
1908\end{array}$ & $\begin{array}{c}18 \\
\text { Oct } \\
1908\end{array}$ & $\begin{array}{c}13 \\
\text { Mar } \\
1910\end{array}$ \\
\hline $1^{\circ}$ Vélez Sársfield & & & & 5 & 28 & 176 & 50 & 54 \\
\hline $\begin{array}{c}2^{\circ} \text { San Cristóbal } \\
\text { Sud }\end{array}$ & 39 & & & 53 & 156 & 546 & 182 & 406 \\
\hline $3^{\circ}$ Santa Lucía & & & & 338 & 343 & 690 & 605 & 869 \\
\hline $\begin{array}{l}4^{\circ} \text { San Juan } \\
\text { Evangelista }\end{array}$ & 830 & & & 510 & 578 & 853 & 775 & 999 \\
\hline $5^{\circ}$ Flores & & & & 64 & 63 & 233 & 111 & 167 \\
\hline $6^{\circ}$ San Carlos Sud & 14 & & & 38 & 115 & 225 & 159 & 417 \\
\hline $\begin{array}{c}7^{\circ} \text { San Carlos } \\
\text { Norte }\end{array}$ & & & 26 & 32 & 78 & 165 & 128 & 249 \\
\hline $\begin{array}{c}8^{\circ} \text { San Cristóbal } \\
\text { Norte }\end{array}$ & 119 & & & 137 & 394 & 726 & 430 & 671 \\
\hline $9^{\circ}$ Balvanera Oeste & & & & 69 & 115 & 538 & 362 & 452 \\
\hline $10^{\circ}$ Balvanera Sud & 110 & & & 64 & 203 & 386 & 401 & 442 \\
\hline $\begin{array}{l}11^{\circ} \text { Balvanera } \\
\text { Norte }\end{array}$ & & 26 & & 85 & 103 & 301 & 192 & 279 \\
\hline $12^{\circ}$ Concepción & 18 & & & 128 & 263 & 479 & 297 & 407 \\
\hline $13^{\circ}$ Monserrat & & & 66 & 110 & 172 & 272 & 286 & 346 \\
\hline $14^{\circ}$ San Nicolás & & & & 179 & 80 & 455 & 333 & 250 \\
\hline $15^{\circ}$ San Bernardo & & & & 2 & 5 & 133 & 8 & 360 \\
\hline $16^{\circ}$ Belgrano & 15 & & & 24 & 38 & 115 & 117 & 235 \\
\hline
\end{tabular}




\begin{tabular}{|c|l|l|l|l|l|l|l|l|}
\hline $17^{\circ}$ Palermo & & & & 13 & 52 & 155 & 130 & 119 \\
\hline $18^{\circ}$ Las Heras & 27 & & & 46 & 278 & 298 & 183 & 329 \\
\hline $19^{\circ}$ Pilar & 82 & & & 117 & 238 & 443 & 419 & 575 \\
\hline $20^{\circ}$ Socorro & & & & 142 & 198 & 386 & 340 & 334 \\
\hline TOTAL & 1254 & 26 & 92 & 2156 & 3500 & 7576 & 5501 & 7960 \\
\hline
\end{tabular}

Fuente: Elaboración propia a partir de datos publicados en La Vanguardia, (15/3/1904, 13/3/1904, 27/11/1906, 11/3/1908, 20/10/1908, 15/3/1910)

Aclaración: Excepto en 1904 y 1905, cuando rigió el sistema uninominal, los electores no votaban por una lista cerrada sino por tantos candidatos como bancas en juego hubiese en cada ocasión. Si bien los votantes solían optar por el conjunto de los candidatos de cada partido, era habitual que hubiera divergencias entre los diferentes candidatos. Además, era habitual que electores no socialistas votaran por Palacios pero no por el resto de los candidatos de la lista socialista. Las fuentes no siempre aclaran qué tipo de cifra es la indicada. Por norma, solía indicarse el promedio. Sin embargo, en algunos casos el periódico o los informes partidarios pueden tomar la cifra del candidato más votado. Eso genera diferencias entre los números dados por La Vanguardia y otras fuentes, como el trabajo de Oddone o un informe enviado por el partido a la Internacional, en 1914, que por lo general muestra números globales algo más bajos (casi con seguridad, debido a la exclusión, para la elaboración del promedio, de los votos obtenidos por Alfredo Palacios). Este cuadro fue elaborado con los datos provistos por La Vanguardia de los días inmediatamente posteriores a cada elección, dado que es la única fuente que informa los votos obtenidos en cada sección.

En marzo de 1904, el PS obtuvo 1.254 de un total de 19.977 votos, es decir más de un 6\%. Se trató de una elección, de todas formas, en las que se votó solamente en 9 de las 19 circunscripciones de la ciudad, dado que la Cámara se renovaba por mitades. Palacios, en la sección $4^{\circ}$, obtuvo 830 votos, es decir el $66 \%$ del total de votos obtenidos por los socialistas ese día, lo cual confirma la interpretación de Torre y Castro sobre la influencia de los votos de otros agrupamientos dirigidos hacia el candidato socialista. Mucho más lejos, Francisco Cúneo sacó 119 votos en la $8^{\circ}$ (San Cristóbal Norte) y Juan B. Justo 110 votos en la $10^{\circ}$. En las seis circunscripciones restantes el partido sumó apenas 195 votos.

Además de celebrar por todo lo alto la consagración de Palacios, La Vanguardia no dejó de hacer una evaluación política sobre lo bajo de los resultados. Por primera vez, las denuncias de fraude cedían lugar a una caracterización sobre lo "mezquino" del resultado socialista. Éste era atribuido a dos causas: " $1^{\circ}$ la depravación política de los obreros argentinos, a consecuencia de una inconciencia espantosa acerca del valor del voto; $2^{\circ}$ la inconsciente repugnancia de los trabajadores 
extranjeros para adquirir la ciudadanía”. La Vanguardia admitía que "positivamente habíamos cifrado mayores esperanzas” para el día de la elección (LV, 15/3/1904).

Luego de dos elecciones complementarias en 1904 y 1905, donde solo se votó en tres secciones en total y con resultados exiguos, la siguiente prueba de fuerza fue la elección parlamentaria de marzo de 1906. Allí, como se observa en el cuadro, los socialistas incrementaron su votación, pero todavía en forma modesta: obtuvieron 2.100 votos — cerca del 5\%-, casi mil más que en la elección anterior, pero ahora en una votación que había incluido a la totalidad de las circunscripciones de la ciudad de Buenos Aires, sumando más de 30.000 votos, y había estado fuertemente disputada entre la Coalición Popular y la Unión Electoral (Cantón y Jorrat, 1999: 441). A fines de ese mismo año, no obstante, se realizaron elecciones complementarias, para elegir dos bancas de diputado que habían quedado vacantes, y la votación de los socialistas se duplicó. En efecto, Del Valle Iberlucea obtuvo 3.677 votos y Pinto 3.313, casi la mitad de los obtenidos por Carlés (8.282) y Cantón (7.471), los candidatos electos por la lista vencedora. Finalmente, los números de la votación socialista alcanzaban incluso a nivel del conjunto de la capital proporciones de importancia. Por primera vez, el partido reconocía el resultado de la elección como un triunfo no solo "moral”. "La significación del partido en la principal ciudad del país es ya evidente para el que tiene un poco de sentido de la realidad política”, celebraba La Vanguardia (LV, 27/11//1906). El Partido Socialista había ganado en La Boca, triplicando a los candidatos coalicionistas, y también en la sección $12^{\circ}$ (Concepción).

En parte el buen resultado se debía al carácter complementario de la elección. "La ocasión es buena”, se ilusionaba La Vanguardia antes del comicio, "porque tratándose solo de llenar dos bancas, los bandos de la política criolla no destinarán tan cuantiosas sumas a la compra de votos como en las elecciones de una lista completa” (LV, 13/10/1906).De todos modos, este ascenso en los resultados electorales se consolidó en la siguiente elección, a principios de 1908, cuando el Partido Socialista volvió a duplicar su votación, pasando a alrededor de 7.500 votos —más del 29\% —, la mitad que los 15.000 obtenidos por los presidencialistas y mucho más que los 1.700 de la Unión Patriótica (Cantón y Jorrat, 1999: 441). Por primera vez, encontramos en La Vanguardia una valoración abiertamente optimista y positiva. El resultado de la elección llenaba a los socialistas “de júbilo y de esperanza”, en tanto habían “duplicado nuestras fuerzas, avanzando y estrechando al enemigo, mientras las camarillas de la oligarquía apenas se han mantenido en sus antiguas posiciones”. Faltaba tan solo "un empuje más y la capital de la república estará conquistada para el Partido Socialista en un plazo muy breve” (LV, 11/3/1908).

La valoración positiva no era exclusiva del periódico partidario. El diario La Razón destacaba que había "llamado mucho la atención la alta cifra de votantes alcanzada ayer por el Partido Socialista”. La Nación, por su parte, sostenía que el PS había hecho "un esfuerzo digno de mencionarse en favor de sus candidatos. Valiéndose de medios lícitos ha llevado a las urnas un número importante de votos”. La Prensa, más alineado con la lista oficial, debía admitir que ésta había encontrado “oposición seria” en "las circunscripciones de San Juan Evangelista [La Boca] y Santa Lucía [Barracas] que constituían el fuerte del Partido Socialista” (LR, 9/3/1908, LN, 9/3/1908, LP, 9/3/1908). 
En parte, la buena elección se debía a que Palacios, que buscaba su reelección, también había sido nominado por una lista independiente. Según La Prensa, "en casi todas partes algunos de los electores borraban un candidato de la lista de la coalición para sustituirlo con el nombre del doctor Alfredo L. Palacios”. La Razón, por su parte, consideraba necesario aclarar que la performance socialista se había visto reforzada por "elementos republicanos, como se ha hecho público y notorio", que votaban "una parte la lista socialista íntegra y otra parte sustituyendo los nombres de algunos candidatos por otros de la agrupación republicana” (LP, 9/3/1908, LR, 9/3/1908).

A fines de 1908 se realizó otra elección complementaria, dado que habían quedado vacantes dos puestos de diputado por la capital. La realización misma de la votación había sido objeto de debate, debido a la reticencia oficial a convocarlas: el Partido Socialista organizó un acto el día 9 de agosto para reclamar la convocatoria a las elecciones, que finalmente fueron realizadas el 18 de octubre. El PS volvió a realizar una importante elección: si bien obtuvo unos dos mil votos menos que en la de comienzos de año, en esta ocasión la participación había sido mucho menor debido a que solo se elegían dos diputados. Se mostraba, una vez más, que en las elecciones complementarias el PS parecía tener más chances de disputar contra unos aparatos oficiales menos incentivados y preparados.

En cualquier caso, la movilización de fuerzas oficialistas en contra de lo que consideraban un posible triunfo de los socialistas alcanzó niveles insospechados. Se trataba, según lo admitían los principales medios de prensa, de un operativo fraudulento que esta vez estaba orientado explícitamente a enfrentar la movilización electoral de los socialistas, en una elección muy

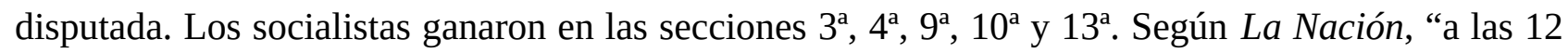
del día estaban equilibradas las fuerzas, pero desde esa hora se comenzó a ejecutar el plan del oficialismo, de volcar los registros en aquellas mesas donde tenían escrutadores de encargo”. El periódico concluía que era "la segunda vez que se produce el espectáculo. En la anterior elección, cuando el Dr. Palacios había obtenido mayoría de votos, fue ahogado bajo el vuelco de padrones. Idéntica cosa ha sucedido ayer” (LN, 18/10/1908).

"El resultado de las elecciones de ayer ha exasperado, como era lógico presumirlo, a los socialistas. Consideran que la lucha ordenada y legal ha terminado, y que para reivindicar sus derechos es necesario recurrir a otros medios”, informaba La Nación (18/10/1908).En efecto, el PS editó un manifiesto en el que denunciaba explícitamente que debido al fraude y la venalidad se le han robado las dos bancas que correspondían a los socialistas. El manifiesto era durísimo con Figueroa Alcorta, a quien acusaba directamente de haber arrebatado las bancas al PS. El partido “acepta, desde hoy en adelante, la situación que le ha creado el gobierno colocándolo fuera de la ley y del orden y se compromete a usar de todos los medios de lucha que las circunstancias aconsejen” (LV, 20/10/1908).

En la última elección que incluimos en el cuadro, en marzo de 1910, el PS volvió a registrar un incremento en su votación, llegando a casi ocho mil votos. Según La Vanguardia, el partido había “escrito la más bella página de civismo que pueda registrar la historia de nuestra democracia inorgánica, en las últimas décadas. Nuestros votos han aumentado y nuestro partido se ha afianzado en la conciencia popular" (LV, 15/3/1910).Los candidatos socialistas obtuvieron una media de 7.000 
votos —el más votado fue Palacios, con 7.945—, mientras los oficialistas promediaron poco más de 23.000 (Cantón y Jorrat, 1999: 441). Si bien el global de votos era el más alto de toda la década un $25 \%$ de los votos, aproximadamente-, esta vez los socialistas se quedarían con el sabor agridulce de no haber podido obtener un triunfo en ninguna de las circunscripciones. En efecto, esta vez incluso en la $4^{\text {a }}$ sección el despliegue de las listas oficialistas había conseguido obtener una victoria por apenas unas decenas de votos.

\section{Conclusión}

Este artículo examinó las prácticas concretas del socialismo argentino en el terreno electoral a partir de un análisis de lo ocurrido en las participaciones del PS en la ciudad de Buenos Aires entre 1896 y 1910. Consideramos que un análisis específico del problema contribuye a echar luz sobre ciertos aspectos de la historia del socialismo argentino en este período temprano. En primer lugar, como vimos, la caracterización que sostiene que el socialismo local no conseguía obtener buenos resultados electorales debido al régimen electoral vigente debe ser matizada. Si esa era la situación en las elecciones previas a 1904, con posterioridad a esa fecha, y aun cuando no pudieran obtener representación parlamentaria — debido a la inexistencia de un sistema proporcional— el PS de la ciudad de Buenos Aires obtuvo resultados destacables, incluso con porcentajes similares a los que obtendría en las décadas posteriores, luego de la Ley Sáenz Peña, aunque claro que en ese caso con una participación total mucho mayor. Este avance electoral en los últimos años de la década de 1900 puede ayudar a comprender, asimismo, la postura reticente y crítica que manifestó el PS ante la reforma electoral, en una primera instancia (Martínez Mazzola, 2015). $\underline{11}$

En segundo lugar, el examen de las prácticas y de la militancia concreta que el PS desenvolvía en torno a las campañas electorales muestra cómo para mediados de la década de 1900 se había convertido en una fuerza de envergadura en los distritos obreros del sur de la ciudad. La cuestión de la participación electoral, en este contexto, adquiere una fisonomía concreta y revela cómo, para los socialistas, las propias campañas electorales eran una ocasión más de disputa política por la conciencia de los trabajadores. La difusión del programa político, la agitación y la propaganda, pero también la movilización de los votantes el día de la elección y la disputa física con los grupos dirigidos por los caudillos de la "política criolla" ponen de relieve que las campañas electorales también eran un episodio de lucha política al interior de la clase obrera, en la cual los socialistas consideraban que era preciso intervenir. Se revela, en suma, la importancia de examinar de manera global las formas concretas que adoptó la disputa política entre tendencias por la conciencia de los trabajadores, en distintos terrenos: las fábricas y talleres, las huelgas, las manifestaciones y los gremios, pero también la lucha política y las elecciones.

Por último, nuestro examen muestra también cómo los planteamientos políticos de los socialistas se vieron a su vez influidos por estas prácticas. La consagración de Palacios en 1904, primero, y el crecimiento electoral observado en los últimos años de la década de 1900, después, reforzaron en el partido una línea política que, como sabemos, otorgaba un lugar preeminente a la vía parlamentaria y que, a la vez, profundizaba su orientación reformista y gradualista. La caracterización de las 
prácticas fraudulentas de los caudillos de la "política criolla” —una categoría que, para los socialistas, englobaba a las distintas facciones que competían entre sí- encajaba a la perfección en la interpretación global que los socialistas hacían de la política, la economía y la sociedad argentinas en la cual debían intervenir. Nadie mejor que Justo para resumir esta caracterización: en un discurso pronunciado en el salón de la Sociedad Democrática Italiana, el 10 de marzo de 1910, el dirigente del socialismo argentino se preguntaba

...¿cómo no esperar una abundante oferta de votos venales de un pueblo empobrecido por los impuestos, huérfanos de ideas políticas, embrutecido y corrompido sistemáticamente por la clase alta? Donde se aplaude la actitud correcta de la policía en una reunión pública porque no mató a nadie, donde dejar votar a los ciudadanos es de parte del gobierno una muestra de magnanimidad, ¿cómo no ha de haber ciudadanos que, junto con ese favor supremo, quieran recibir unos pesos? Donde el candidato “popular” es el presidente del Jockey Club, ¿por qué no recabarle en cambio del voto el importe de unos boletos que hagan honor en el hipódromo a los colores de su stud? La venalidad electoral es uno de los caracteres de la última fase de la política criolla, y esta no puede desaparecer sino por obra de un movimiento que, como el movimiento socialista, infunda al pueblo trabajador nuevos sentimientos de altivez, nuevas ideas de lucha, nuevas capacidades para la acción. $\underline{12}$

El "fraude", en efecto, siempre era visto como una rémora de un pasado arcaico que debía ser superado, una maniobra propia de una burguesía "rapaz e ignorante” que no era capaz de comprender las líneas del progreso que el mismo capitalismo traía consigo. Una vez más, era el socialismo el que debía cumplir un rol pedagógico para con la propia burguesía, difundiendo y expandiendo las virtudes de unas prácticas electorales “sanas”. La caracterización según la cual el PS mostraba un "temprano compromiso con las prácticas de la vida política del régimen oligárquico”, que "legitimaba el fraude y la corrupción” (Torre, 2012), no se corresponde con la práctica política del partido en este período, que denunciaba en forma habitual a las fuerzas del régimen, y se enfrentaba con ellas en un terreno también físico. Es indudable, no obstante, y quizás más importante, que esta dura y permanente denuncia de la "política criolla” y sus mecanismos fraudulentos no incluía en ningún caso una problematización ni un cuestionamiento de la democracia burguesa como tal, lo que se revelaría como una de las claves políticas decisivas para comprender la profundización del camino reformista por parte del PS en las décadas subsiguientes.

\section{Notas}

1 Sobre las primeras etapas del movimiento obrero en Argentina, ver entre otros Marotta (1960), Falcón (1984), Korzeniewicz (1989), Andreassi Cieri (1997) y Poy (2014). Acerca del Partido Socialista en esta etapa, ver Walter (1977), Oddone (1983), Adelman (1992), Aricó (1999), Camarero y Herrera (2005), Tarcus (2007), Graciano (2010), Falcón (2011) y Poy (2015a). Para una mirada global sobre la socialdemocracia internacional, ver entre otros Procacci (1958), Haupt (1964), Cole (1964), Joll (1966), Steenson (1991) y Callahan (2010). 
$\underline{2}$ Sobre las características del régimen político de la época, en general, y el funcionamiento de los procesos electorales en particular ver, entre otros, Botana (1977), Sabato y Palti (1990), Alonso (1997), Cantón y Jorrat (2004), Castro (2012). Sobre la campaña del Partido Socialista en favor de la naturalización de los extranjeros, ver Poy (2015b).

$\underline{3}$ Richard Walter apenas dedicó algunos comentarios marginales sobre las campañas electorales en el período previo a 1912, y se concentró mucho más en el trabajo de Palacios dentro del congreso (1977: 28-30 y 64-65). El clásico y pionero trabajo de Jacinto Oddone sí le dedicó un capítulo específico a la cuestión (1983, 193-239), que completaba y ampliaba lo incluido en un folleto editado por el propio partido en 1910. Sobre la consagración de Palacios en 1904, ver Torre (2012).

4 Algo similar había caracterizado el dirigente anarquista-y ex socialista- Eduardo Gilimón en 1910. Desde su perspectiva, Palacios había sido elevado al cargo de diputado, "por una condescendencia del gobierno que permitió se presentaran tres candidatos gubernistas por la misma circunscripción, lo que naturalmente fraccionó mucho sus fuerzas; y gracias a los votos de otras agrupaciones partidistas de oposición que se plegaron a la candidatura socialista” (1910: 55-56).

$\underline{5}$ El 29 de noviembre de 1903 se habían realizado elecciones municipales en la provincia de Buenos Aires. Los socialistas se presentaron en Barracas al Sud, Baradero y San Nicolás. Con 65 votos, y a pesar de las prácticas habituales de fraude, en esta última localidad alcanzó para hacer ingresar un concejal socialista (Agustín Reynés).

6 En su tipología sobre el grado de “competitividad” de las elecciones del período 1864-1910, Cantón y Jorrat les asignan el nivel “medio y alto” a las del período que se extiende desde 1904 hasta 1910 (2004: 13).

Z En 1906, La Vanguardia decía sobre Flores que era un “pueblo ‘aristocrático’, centro de familias tradicionales, [donde] los politicastros de la coalición encontraron excelente terreno para desenvolver sus planes. Casi todos los escrutadores son empleados públicos. Así se explica que obtuvieran 445 votos y 63 los socialistas” (LV, 27/11/1906).

$\underline{8}$ Para un análisis más amplio sobre las caracterizaciones socialistas respecto al derecho de las mujeres al sufragio, ver Barrancos (2005).

9 Un aspecto especialmente interesante es la denuncia que los socialistas hacían, en ocasión de las crónicas de las jornadas electorales, hacia sus adversarios políticos al interior del movimiento obrero. En efecto, tanto anarquistas como sindicalistas revolucionarios, conocidos por su fuerte oposición a la lucha política, eran a menudo denunciados por permitir, con su omisión o a veces directamente con sus acciones, que los trabajadores se convirtieran en "instrumentos" de la "política criolla”. En marzo de 1906, por ejemplo, La Vanguardia denunciaba a “algunos carreros que días antes se abstendrían de votar, allí estaban también recibiendo el pago de su villanía. ¡Esos mismos que protestaban cuando los cosacos asaltaban el local de los carreros!”. Dos años más tarde, se volvía a acusar a militantes del mismo gremio y del mismo barrio de Barracas. Según La Vanguardia, la acción de los caudillos oficialistas no había impedido "que los trabajadores dieran su voto por el Partido Socialista, haciendo caso omiso de la propaganda contraria que los "anarquistas" 
elementos de Balestra realizaban desde el local de los conductores de carros, aconsejando no votar por los socialistas, pero estimulando a los electores para que votaran por la lista oficial”. En el meeting de protesta que los socialistas celebraron para denunciar el fraude electoral, el 15 de marzo de 1908, Zaccagnini explícitamente "fustigó a ciertos elementos que suelen perorar en agrupaciones de tendencias avanzadas y que en las elecciones cooperaban a impedir el triunfo de los socialistas, prestándose a votar por la lista oficial” (LN, 16/3/1908).

10 En 1898, de todos modos, el Comité Electoral del partido había publicado un cómputo propio sobre los votos obtenidos: según los socialistas, habían obtenido un total de 1.387 votos, mientras formalmente se le habían reconocido poco más de cien. Informaban cifras con detalle, indicando que sus puntos más altos eran San Telmo (281), San Cristóbal (223) y Balvanera Norte (151).

11 Para un análisis de la coyuntura de 1910-1912 y el camino a la reforma, ver Devoto (1996), Gallo (2000) y Castro (2004 y 2012).

12 Archivo de Dardo Cúneo, Biblioteca Nacional Mariano Moreno, Buenos Aires.

\section{Periódicos citados}

La Vanguardia (LV)

La Prensa (LP)

La Razón (LR)

La Nación (LN)

\section{Referencias}

Adelman, J. (1992). Socialism and Democracy in Argentina in the Age of the Second International.The Hispanic American Historical Review, vol. 72 (2).

Alonso, P. (1996). Voting in Buenos Aires, before 1912. En Posada Carbó. E. (ed.) Elections before Democracy: The History of Elections in Europe and Latin America. Nueva York: St. Martin's.

Andreassi Cieri, A. (1997). La rebelión de los metecos. Conflictividad laboral y social en Buenos Aires, 1895-1910. Barcelona: CIMS.

Aricó, J. (1999). La hipótesis de Justo: escritos sobre el socialismo en America Latina. Buenos Aires: Sudamericana.

Barrancos, D. (2005). Socialismo y sufragio femenino. Notas para su historia (1890-1947). En Camarero, H. y Herrera, C. (eds.) El Partido Socialista en Argentina. Buenos Aires: Prometeo, pp. 159-183. 
Botana, N. (1977). El orden conservador: la política argentina entre 1880 y 1916. Buenos Aires: Sudamericana.

Callahan, K. J. (2010). Demonstration Culture. European Socialism And The Second International, 1889-1914, Leicester: Troubador Publishing.

Camarero H. y Herrera, C. (eds.) (2005). El Partido Socialista en Argentina: Sociedad, política e ideas a través de un siglo. Buenos Aires: Prometeo.

Cantón, D. y Jorrat, J. (1999) Buenos Aires en tiempos del voto venal: elecciones y partidos entre 1904 y 1910. Desarrollo Económico, vol. 39 (155).

Cantón, D. y Jorrat, J. (2004). Clase social y voto en la ciudad de Buenos Aires, 1864-1910. Revista SAAP, vol. 2 (1), pp. 11-33.

Castro, M. O. (2007). Liberados de su 'bastilla': saenzpeñismo, reformismo electoral y fragmentación de la elite política en torno al Centenario. Entrepasados, revista de Historia, n. 31.

Castro, M. O. (2012). El ocaso de la república oligárquica: poder, política y reforma electoral, 18981912. Buenos Aires: Edhasa.

Cole, G.D.H. (1964). Historia del pensamiento socialista: III : la segunda internacional, 1889-1914. México, Fondo de Cultura Económica.

De Privitellio, L. (2006). Representación política, orden y progreso. La reforma electoral de 1902”. Política y Gestión, Revista de la Escuela de Política y Gobierno de la Universidad Nacional de San Martín, vol. 9.

Devoto, F. (1996). De nuevo el acontecimiento: Roque Sáenz Peña, la reforma electoral y el momento político de 1912. Boletín del Instituto de Historia Argentina y Americana "Dr. Emilio Ravignani". 3rd ser., 14.

Falcón, R. (1984). Los orígenes del movimiento obrero (1857-1899), Buenos Aires: CEAL.

Falcón, R. (1987). Izquierdas, régimen político, cuestión étnica y cuestión social en la Argentina. Anuario de la Escuela de Historia, núm. 12.

Falcón, R. (2011). Orígenes del movimiento socialista en Argentina. Prólogo. Capítulo I y II. Cuadernos del Ciesal, año 8, número 10, pp. 11-45.

Gallo, E. (2000). La consolidación del Estado y la reforma política (1880-1914). En Academia Nacional de la Historia, Nueva Historia de la Nación Argentina. Buenos Aires, Planeta, vol. 4.

Gilimón, E. (1910). Hechos y comentarios, Buenos Aires.

Graciano, O. (2010). El Partido Socialista de Argentina: su trayectoria histórica y sus desafíos políticos en las primeras décadas del siglo XX”. A contra corriente, vol. 7 (3), pp. 1-37.

Haupt, G. (1964). La Deuxième Internationale, 1889-1914: étude critique des sources, essai bibliographique. Paris: Mouton. 
Joll, J. (1966). The Second International, 1889-1914. New York, Harper \& Row.

Korzeniewicz, R. (1989). Labor Unrest in Argentina, 1887-1907, Latin American Research Review, vol. 24 (3).

Marotta, S. (1960). El movimiento sindical argentino. Su génesis y desarrollo, 1857-1907, Buenos Aires: Editorial Lacio.

Martínez Mazzola, R. (2015). ¿Males pasajeros? El Partido Socialista frente a las consecuencias de la Ley Sáenz Peña. Archivos de historia del movimiento obrero y la izquierda, año III, núm. 6, pp. 53-72.

Oddone, J. (1983). Historia del socialismo argentino. Buenos Aires: CEAL, 1983.

Poy, L. (2014). Los orígenes de la clase obrera argentina. Huelgas, sociedades de resistencia y militancia política en Buenos Aires, 1888-1896, Buenos Aires: Imago Mundi.

Poy, L. (2015a). Los primeros congresos del Partido Socialista argentino(1896-1908): Consideraciones para un análisis social y político. European Review of Latin American and Caribbean Studies, n. 99, pp. 47-67

Poy, L. (2015b). Ciudadanía, derechos politicos y conciencia de clase. La cuestión de la naturalización de los extranjeros en los orígenes del socialismo argentino. Diálogos. Revista electrónica de Historia, vol. 16 (2), pp. 3-29.

Procacci, G. (1958). Studi sulla Seconda Internazionale e sulla Socialdemocrazia tedesca.Annali, n. 1, pp. 105-146.

Rojkind, I. (2006). Prensa, manifestaciones y oposición política. La protesta contra la unificación de la deuda en julio de 1901. Estudios Sociales, vol. 31 (1).

Sabato, H. y Palti, E. (1990). ¿Quién votaba en Buenos Aires?: Práctica y teoría del sufragio, 18501880. Desarrollo Económico, vol. 30 (119), pp. 395-424.

Steenson, G.(1991).After Marx, before Lenin: Marxism and socialist working-class parties in Europe, 1884-1914. Pittsburgh: University of Pittsburgh Press.

Tarcus, H. (2007). Marx en la Argentina. Buenos Aires: Siglo XXI.

Torre, J.C. (2012). Ensayos sobre movimiento obrero y peronismo, Buenos Aires: Siglo XXI.

Walter, R. J. (1977). The Socialist Party of Argentina, 1890-1930. Austin: Institute of Latin American Studies, University of Texas. 